Aceptar el desafío de la Ciencia y no conformarse dentro de los límites actuales, seguramente impulsará al poeta a nuevos problemas y a nuevas conquistas. Lo que se gane o se pierda, siempre ha de prosperar en un futuro, ya que sólo nos corresponde acrecentar la herencia de la persona humana y ayudarla a promover sus valores supremos.

\title{
NICANOR PARRA
}

\section{POETAS DE LA CLARIDAD}

EL AÑo 1938, que en el curso del Encuentro de Escritores ha sido considerado por algunos como una fecha de gran significado político, desde que marca el advenimiento del Frente Popular al poder, es también para un grupo de poetas, que ahora tiene poco más o poco menos de cuarenta años, un momento de singular importancia literaria; me refiero a la publicación, por parte de la Sociedad de Escritores de Chile, de una antología de los poetas jóvenes de aquel entonces. Desde un punto de vista material, la antología no tenía nada d’ extraordinario, puesto que no iba más allá de ser un simple número de la revista de la institución; pero su sentido espiritual, hoy en día no podríamos dejar de reconocerlo, fue para nosotros muy profundo. En ella figuraban ocho poetas noveles: Luis Oyarzún, Jorge Millas, Omar Cerda, Victoriano Vicario, Hernán Cañas, Alberto Baeza Flores, Oscar Castro y el que habla.

Para varios de nosotros, la antologia tenía el valor de un espaldarazo, puesto que ella aparecía patrocinada por la institución literaria de mayor autoridad que existe en el país. Más aún, la selección, el prólogo y las notas de presentación de los poetas iban firmados por un escritor consagrado, poeta y ensayista, que pocos años antes había publicado una obra en colaboración con Pablo Neruda - Anillos-, vate que en aquel entonces era considerado ya por muchos como uno de los primeros poetas de Chile. Se trata de Tomás Lago.

A excepción de Oyarzún, que era el más joven, y de Hernán Cañas, cada uno de los poetas antologados había publicado ya su primer libro. Jorge Millas, sus “Trabajos y los Días", libro impregnado de alusiones filosóficas, circunstancia que lo adscribía a la corriente poética iniciada en Chile por Humberto Díaz Casanueva. Se le emparentaba con Paul Valéry, príncipe de la poesía francesa de la época, por quien Millas profesaba una admiración 
religiosa. Omar Cerda, su "Porvenir de Diamante", obra de ascendencia albertiana, gongorina y garcía-lorquiana, según la opinión de Hernán Diaz Arrieta. Victoriano Vicario, su "Lamparero Alucinado", dentro del mundo espiritual de Jacobo Danke, es decir, de Milosz, traducido al castellano por D'Halmar, y dentro también de la órbita de Lord Dunsany, cuyas “Memorias de un Soñador" devoramos con avidez. Alberto Baeza Flores, su "Experiencia de Sueño y Destino", obra de cierta dimensión onírica, como el título mismo lo sugiere. Oscar Castro también se había dado a conocer. Su libro "Viaje del Alba a la Noche", había competido el año anterior con mi "Cancionero sin Nombre", por el Premio Municipal de Poesía. Tanto Castro como yo, mostrábamos una influencia innegable del poeta mártir de la Guerra Española, Federico Garcia Lorca.

Pero no es el fenómeno físico de la publicación de la Antología al que quicro referirme en esta oportunidad, sino al significado polémico de los postulados que ella planteaba tácitamente. Porque no se trataba de una selección hecha con criterio ecléctico por un cronista literario, puesto que en tal caso no habrian podido dejar de figurar en ella los poetas del grupo Mandrágora, que eran mucho más maduros que nosotros, más navegados y más relacionados. Hablo de Braulio Arenas, Gonzalo Rojas (el Gonzalo Rojas de entonces), Enrique Gómez, Teófilo Cid, Jorge Cáceres. Ni los poetas del grupo David, formado por un solo elemento: Eduardo Anguita, que ya se había autoinmortalizado, incluyéndose a sí mismo en la gran “Antología de la Poesía Chilena Nueva", junto a Vicente Huidobro, Pablo Neruda, Pablo de Rokha, Humberto Díaz Casanueva, Rosamel rel Valle, Omar Cáceres, Juvencio Valle, Angel Cruchaga Santa María y Volodia Teitelboim, coautor de la obra (Gabriela Mistral, por razones incomprensibles en la actualidad, no figuraba en el Olimpo de Anguita y Teitelboim).

¿Qué laya de sujetos eran los poetas antologados por Tomás Lago? No es difícil describirlos. Políticamente éramos en general apolíticos, más exactamente, izquierdistas no militantes; en materia religiosa no éramos católicos: la teología nos tenía sin cuidado, aunque no tanto. Yo me inclinaba por la filosofia oriental, lo que me hacía sospechoso frente a mis compañeros más intimos: Oyarzún y Millas. Por su parte, Oyarzún creía en los cíclopes, tal como suena, y Millas, a pesar de su sólida formación académica, se dejaba deslumbrar por un filósofo ambulante de la Quinta Normal, que afirmaba que el hombre debía inspirarse en los animales domésticos en materia de modales personales: del gallo debía aprender la gallardía, y del caballo, la caballerosidad. 
¿Qué era, entonces, lo que nos hacia considerables a los ojos del antologador? La mera virtud poética, se comprende, pero dentro de ella, el canon de la claridad conceptual y formal.

A cinco años de la antología de los poetas creacionistas, versolibristas, herméticos, oníricos, sacerdotales, representábamos un tipo de poetas espontáneos, naturales, al alcance del grueso público. Oscar Castro, el más afortunado del grupo, figuraba en los repertorios de todas las recitadoras profesionales y privadas. Hernán Cañas, Omar Cerda y el que habla, habiamos sido poetas laureados en los Concursos Primaverales de los Estudiantes. Claro que no traíamos nada nuevo a la poesia chilena. Significábamos, en general, un paso atrás, a excepción de Millas y de Oyarzún, que, según mi modo de ver, eran ya unos poetas perfectamente vertebrados. Nos hallábamos más cerca de Cruchaga, que era el poeta menos atrevido de nuestros mayores, que de los innovadores realmente significativos. Carlos Poblete, en su "Panorama de la Poesía Chilena Actual", publicado poco después en Buenos Aires, refiriéndose a mi, expresaba: "Cabeza visible de una plaga de guitarreros que han invadido la poesía chilena últimamente. Poesía periférica, superficial, como todo lo que no se nutre de la esencia profunda del hombre". Esas palabras me llegaron a la médula.

Pero nuestra debilidad inicial, así lo pienso en la actualidad, era un punto de partida legitimo para nuestra evolución ulterior. En ella radicaba la fuerza que más tarde nos ha dado derecho a la vida. Fundamentalmente, creo que teníamos razón al declararnos tácitamente, al menos, paladines de la claridad y la naturalidad de los medios expresivos. Por lo menos, en esa dirección se ha movido posteriormente el cuerpo de las ideas estéticas chilenas. Tomás Lago, que en el año 1939, había aceptado, más por compromiso que por convicción, redactar el prólogo de media página de la Antología, un poco a regañadientes, se transforma en 1942 en el adalid de la nueva doctrina, cuyo contenido sintetizó él mismo en la frase "Luz en la Poesia", con que tituló el prefacio de sus "3 Poctas Chilenos", obrita de bolsillo, editada primero por Arturo Soria, de la Cruz del Sur. El título de ese prefacio no era arbitrario; en esos mismos días, el que habla había anunciado un libro denominado "La Luz del Día". Ese libro no vio nunca la luz del dia, pero, aumentado y disminuido, pasó más tarde a formar parte de "Poemas y Antipoemas".

El credo de la poesía diurna, como ahora me atrevo a llamarla, surgía según nuestro exégeta, de poemas como "Hay un Dia Feliz", "Es Olvido", "Se Canta al Mar", y en él se fustigaba a los poetas nocturnos, es decir, a 
los poetas rebeldes de la antología de Anguita. De más está decir que nosotros constituíamos el reverso de la medalla surrealista.

Hoy, a veinte años de distancia de esos días turbulentos y decisivos en nuestros vacilantes destinos literarios, estamos en condiciones de juzgar con un poco de paciencia el caso, y determinar el grado de razón que contenían nuestros preceptos estéticos. En líneas generales, no sería justo decir que hemos claudicado. Por el contrario, nos hemos ido fortaleciendo año a año en nuestras convicciones juveniles medulares. Los hechos se han encargado de demostrar que por lo menos el cincuenta por ciento de nuestros principios no habia sido mal ideado. El otro cincuenta por ciento, y ésta es la idea que quiero aportar a la Reunión de Escritores, el otro cincuenta por ciento, repito, estaba de parte de los surrealistas, que en aquella época representaban, en rigor, el paso siguiente del creacionismo y del nerudismo: la inmersión en las profundidades del subconsciente colectivo.

Para sobrevivir, tuvimos que absorber las enseñanzas de Freud, componente central del surrealismo mandragórico. Pero ellos también tuvieron que cedernos un poco de terreno a nosotros. No es producto de la casualidad el hecho de que Gonzalo Rojas y el que habla sigan interesados vivamente en el proceso de la creación poética. En conversaciones de Los Guindos, Gonzalo me entregó la llave del templo de la poesía negra, pero yo aticé en él el fuego de la poesía blanca.

¿Y los demás? Bueno, algunos abandonaron la partida. Otros han seguido insistiendo tercamente en sus formulaciones primitivas. Muchos de ellos han carecido de la flexibilidad intelectual requerida para adaptarse a las nuevas modalidades expresivas.

Nosotros mismos, tampoco podemos vanagloriarnos de haber ganado la batalla. El antipoema, que, a la postre, no es otra cosa que el poema tradicional enriquecido con la savia surrealista -surrealismo criollo o como queráis llamarlo- debe aún ser resuelto desde el punto de vista psicológico y social del país y del continente a que pertenecemos, para que pueda ser considerado como un verdadero ideal poético. Falta por demostrar que el hijo del matrimonio del día y la noche, celebrado en el ámbito del antipoema, no es una nueva forma de crepúsculo, sino un nuevo tipo de amanecer poético. 